AJChE 2017, Vol. 17, No. 2, 60 - 76

\title{
Open Loop Recycling of Recycled Polypropylene for Motorcycle Saddle Application
}

\author{
Piyachat Wattanachai *,1 \\ Benjawan Buasathain ${ }^{1}$ \\ Christian Antonio ${ }^{2}$ \\ Susan Roces ${ }^{3}$ \\ ${ }^{1}$ Department of Chemical Engineering, Faculty of Engineering, Burapha University, Sean Sook, \\ Muang, Chonburi 20131, Thailand \\ 2 University of Queensland, Brisbane, QLD 4068, Australia \\ ${ }^{3}$ Department of Chemical Engineering, De La Salle University, Manila 0922, Philippines \\ *e-mail: piyachat.a@eng.buu.ac.th
}

This research investigated the possibility of using polymer blends of virgin and recycled polypropylene (PP) for a motorcycle saddle application. Three different recycled PPs obtained from different sources contained carbon black (CB). Specimens were prepared by injection molding for mechanical property testing and color characterization whereas scraps from runners were used for thermal property testing. It was found that tensile and flexural properties of recycled PPs were better than those of virgin PP due to the fact that recycled PPs contained CB which is a reinforcing material. These properties were improved as the amount of recycled PP added increased. Since recycled PPs are strong materials, they are hence brittle resulting in lowering impact strength and percent elongation. The recycled PP sources and compatibility between virgin and recycled PPs strongly influence the blends' properties. The melt flow index of the blends increased as the amount of the recycled PP increased because of the short polymer chains of recycled PP resulting from earlier processing. Blending virgin PP with recycled PP not only improves its properties, but also reduces raw material costs in the range of $5-13 \%$. The advantage of open loop recycling is a wider recycled plastic market.

Keywords : Polypropylene, recycled plastics, motorcycle parts, polymer blends, open loop recycling

\section{INTRODUCTION}

Due to the ever increasing consumption of plastics, plastic recycling has drawn much interest over the last few decades. Society is fully aware of the impacts of plastic wastes, not only on human health but also on energy conservation as well as manufacturing cost reduction. The production and consumption of various virgin plastics have been growing steadily because they 
are replacing other materials due to several beneficial advantages (Subramanian 2000). Plastics are inexpensive and easy to synthesize and to process compared to metals and ceramics. They are also light weight with considerably good mechanical properties. Their properties can be modified easily as many types of polymer composites exist (Jancar et al. 2010, Reinforced Plastic 2003). The significant increase in usage of plastics in society has necessitated plastic waste recycling. Several environmental impact evaluations of plastic waste mainly through a Life Cycle Assessment approach have been undertaken (Rajendran et al. 2012, Rigamonti et al. 2014) and a number of experimental studies on properties of recycled plastics has been carried out (Meran et al. 2008, Madi 2013, Brachet et al. 2013, Tao and Mai 2007). As a result, there has been a growing number of recycled plastic usage in various industries (Subramanian 2000, Sten 1992). Automotive manufacturers are one of the major industries making efforts to produce vehicles from recyclable materials (Subramanian 2000, Plastic Addict Compound 2003) and accordingly the amount of recycled plastic parts in vehicles has increased from $2 \%$ to $13 \%$ from 1965 1995 (Sten 1992). However, there are several challenges in the recycling of plastics that are yet to be overcome (Subramanian 2000, Rajendran et al. 2012, Sten 1992). In general, plastic wastes from various sources are contaminated either by different types of polymers or different materials. Waste collection, identification, separation, and purification are time consuming, require costly technologies, and expensive. Furthermore, there is the added difficulty or inability of extracting reinforcing materials and additives out of polymer composites. Hence the recycled material market is not as strong as the virgin resin market (Sten 1992, Plastic Addict Compound 2003). Due to the fact that hundreds, if not thousands, of different polymers and polymer blends have been formulated and the development of new polymer blends and composites to serve the high demands from various industries and applications will be ongoing, the current issues in plastic waste recycling will become even more complex and require immediate attention.

Among the extensive range of commercial polymers, polypropylene (PP) is the third largest variety in terms of plastic consumptions and plastic wastes (Subramanian 2000, Meran et al. 2008, Brachet et al. 2013). PP has several superior properties including very good mechanical properties, durability, chemical resistance, and ease of processibility and is widely used in packaging, electrical appliances, agriculture, textile and automotive applications. However, its deficiencies include limited thermal stability and flammability. Consequently, several additives have been utilised to overcome these drawbacks (Brachet et al. 2013, Deng et al. 2009, Zhang et al. 2006, Palza 2010). Carbon black (CB) is one of the most common materials used as a filler and also used as a pigment and most importantly as a reinforcing agent due to its abundance, lightweightness, and low cost. Its usage is quite versatile from improving electrical conductivity, 
mechanical properties, and chemical properties to improving thermal and UV stabilities of materials (Wen et al. 2012, Liu et al. 2010, Jakab and Omastova 2005). The most common application of CB is in automobile rubber tires as a reinforcing material due to its ability to significantly improve rubber mechanical properties (Semaan et al. 2002, Omnès et al. 2008). For plastics parts in electrical appliances and automotives, $C B$ is also frequently used as a pigment, as a flame retardant and as a thermal stabilizer. The benefits of $C B$ on the mechanical properties of plastics has been studied and reported (Liu et al. 2010, Reffaee 2009). The delay in the thermal decomposition of $\mathrm{PP} / \mathrm{CB}$ nanocomposites especially in an environment of air compared to those of pure PP implied that the addition of $C B$ significantly improved thermal stability of the composites (Wen et al. 2012, Jakab and Omastova 2005, Chrissafis 2007). The geometry of the carbon is quite important as studies indicate properties such as flame retardance and electrical conductivities are improved when carbon is used in the form of carbon nanotubes (CNTs) as compared to CB (Socher et al. 2011, Kashiwagi et al. 2004, Marinho et al. 2012, Thaithae et al. 2016). The enhancement in the thermal and electrical properties of polymer composites was attributed as an effect of the crystallization behavior. $C B$ acts as a nucleating agent and hence the crystallization temperature of CB/PP was higher than that of neat PP, however, the crystallization temperature was independent of the amount and type of carbon fillers whereas the melting temperature changed slightly with the amount of filler (Deng et al. 2009, Chrissafis 2007, Razavi-Nouri et al. 2009). At high CB loadings, the melting temperature and degree of crystallinity decreased as the $C B$ particles act as a restriction site and prevent macromolecular segments to form an alignment of crystal lattices (Liu et al. 2010).

PP is considered as a commodity polymer, however, it has better properties compared to those of low and high density polyethylene (LDPE and HDPE) and hence, it has been used in more advanced applications rather than just household goods. In the automotive sector, glass fiber/PP composites are commonly used as automobile radiator tanks, body panels, closures, bumpers, and battery cases. A number of studies have focused on recycled PP from post-consumer waste due to two reasons: 1) PP is a strong thermoplastic (can be recycled) and 2) European Union legislation is aiming for new vehicles to be made of recyclable materials (Plastic Addict Compounds 2003). While closed loop recycling is restricted to the usages of recycled PP, open loop recycling broadens the recycled PP markets and hence is still going strong. $\mathrm{Ha}$ (2012) applied post-consumer waste PP to refrigerator parts and found comparable mechanical properties to pure virgin PP. Experimental findings indicated that among LDPE, HDPE, and PP, the material which can be most successfully recycled is PP (Meran et al. 2008). As the mechanical properties of recycled PP deteriorates due to chain scission, optimization of mechanical properties of recycle/virgin PP blends could be achieved 
by either optimizing the process parameters (Gu et al. 2014) or chemical modification (Madi 2013, Al-Saleh and Sundararaj 2008). Recycled PPs from post-consumer containers were modified with an elastomer and calcium carbonate to obtain the required quality for buckets in close loop recycling, however, the presence of impurities hindered any improvements (Brachet et al. 2013). The closed loop recycling of PP for automotive battery cases has been carried out by Rust et al. (2006) and Ferg and Bolo (2013) who concluded that the melt flow index (MFI) was a good and easy technique for identifying flow properties and hence can be used as a tool for quality control of the battery cases. This research, hence, focused on the feasibility of open loop recycling using various recycled $\mathrm{PP}$ to blend with virgin PP for the manufacture of motorcycle saddles and determine how their mechanical and flow properties compare to current manufacturing standards.

\section{EXPERIMENTAL}

\section{Materials}

Virgin PP grade PP2500H was purchased from IRPC Co., Ltd. Thailand and a PP master batch containing carbon black (Black MLBL-0015) was provided by Sekai Color Co., Ltd. Three recycled PP grades (PP-041B, PP-042B, and PP-043B) containing $C B$ made from recycled packaging, electrical appliance parts, and automotive parts, respectively, were supplied by Master-Tech Chemical Co., Ltd. These recycled PP grades came without any additional fillers or modifiers.

\section{Sample Preparation}

$1 \mathrm{~kg}$ mixtures of virgin PP resin with different loadings of recycled PP ranging from $0-100 w t \%$ were prepared using the following procedure. The two PPs were weighed and mixed using a SWMX 25 mixer for 5 minutes prior to the injection process. A Toshiba injection machine model SM 120 was used to prepare testing specimens together with a mold cavity comprising of $5 \times$ tensile testing specimens (ASTM D638), $5 \times$ flexural testing specimens (ASTM D792), $10 \mathrm{x}$ impact testing specimens (ASTM D256), and a specimen for color analysis measuring $50 \mathrm{~mm}$ in diameter and $3.2 \mathrm{~mm}$ thick. Runners were ground into small pieces for thermal characterization. As for a reference (benchmark), a mixture of the virgin $\mathrm{PP}$ and the $\mathrm{PP} / \mathrm{CB}$ master batch was prepared with a composition equivalent to 3 wt\% CB and was processed in the same way as the virgin/recycled blends.

\section{Carbon Black Content}

Due to the fact that $C B$ is required for the motorcycle saddle as a pigment filler as well as a reinforcing material, all three recycled PP grades were derived from those sources containing $C B$ and hence no additional $C B$ was incorporated. The characterization of $C B$ content in the three recycled PPs was performed using a TA Instruments Thermogravimetric Analyzer (TGA). 8-15 mg samples were heated from room temperature up to $1000^{\circ} \mathrm{C}$ at a heating rate of $10^{\circ} \mathrm{C} / \mathrm{min}$ in a nitrogen environment. 


\section{Mechanical Properties Testing}

An EMIC universal testing machine model DL2000/1000 was utilized for tensile testing according to ASTM D638 to measure tensile strength, Young's modulus, and \% elongation at break. The specimens prepared from injection molding were tested at a tensile speed of $50 \mathrm{~mm} / \mathrm{min}$. Flexural strength and flexural modulus analysis were performed according to ASTM D792 in which a $5 \mathrm{kN}$ load cell was used. The span of the two supports was $50 \mathrm{~mm}$ and the compression speed was $15 \mathrm{~mm} / \mathrm{min}$. For both tensile and flexural tests, 5 pieces of specimen for each were tested to obtain average values and standard deviations. 10 pieces of specimen were tested for the impact test using a Cometech Izod Impact Strength unit according to ASTM D256 using an impact energy of $2.7 \mathrm{~J}$.

\section{Thermal Characterization}

The melt flow index (MFI) of PP was tested at a die temperature of $230^{\circ} \mathrm{C}$ with a load of $2.16 \mathrm{~kg}$ according to ASTM D1238. The ground runner was filled in the chamber of a Jinan PTE Melt Flow Indexer model XRL-400B and the test was performed 10 times to get the average $\mathrm{MFI}$. Melting temperature $\left(\mathrm{T}_{\mathrm{m}}\right)$, degree of crystallinity, crystallization temperature $\left(T_{c}\right)$ were examined using a Perkin Elmer Differential Scanning Calorimeter (DSC) model DSC-800 following ASTM D3418. 5-8 mg of ground runner was tested with 3 heating-cooling cycles under a nitrogen atmosphere. The first cycle started at $25^{\circ} \mathrm{C}$ with a heating rate of $10^{\circ} \mathrm{C} / \mathrm{min}$ up to $220^{\circ} \mathrm{C}$ where the sample was held for 5 minutes. The second cycle was the cooling of the sample from $220^{\circ} \mathrm{C}$ to $25^{\circ} \mathrm{C}$ at a cooling rate of $10^{\circ} \mathrm{C} / \mathrm{min}$. The sample was then reheated using the same condition as the first cycle. The \% crystallinity was calculated from the heat of fusion (melting) $\left(\Delta \mathrm{H}_{\mathrm{f}}\right)$ and the literature value of $100 \%$ crystalline PP $(207 \mathrm{~J} / \mathrm{g}$ ) as shown in Eq. (1).

$\%$ crystallinity $=\frac{\Delta \mathrm{H}_{100 \%}-\Delta \mathrm{H}_{\mathrm{f}}}{\Delta \mathrm{H}_{100 \%}}$

\section{Color Measurement}

A Konica Minolta model CR-400/CR410 Chroma Meter was used for color measurement according to the CIELAB 1976 method. The result of interest is the deviation of the color ( $\mathrm{dE}$ ) compared to the customer's standard for a motorcycle saddle color. Five measurements at 5 different positions on the specimens were carried out to obtain an average value.

\section{RESULTS AND DISCUSSION}

\section{Carbon Black Composition}

The TGA results of the two recycled PPs, PP-041B and PP-042B which are the wastes of packaging and electrical appliances, respectively, were found to contain approximately $10 \mathrm{wt} \% \mathrm{CB}$ as well as approximately $5 \mathrm{wt} \%$ calcium carbonate $\left(\mathrm{CaCO}_{3}\right)$ which decomposed around 600$700^{\circ} \mathrm{C}$ as shown in Figure 1. $\mathrm{CaCO}_{3}$ is generally used as a filler to improve plastic properties but also to reduce cost; however, it is not an effective reinforcing material compared to CB. PP-043B which is the waste from automotive parts, on the other hand, consisted of only 3 wt\% CB and contained no $\mathrm{CaCO}_{3}$. The thermal decomposition temperatures of the three 

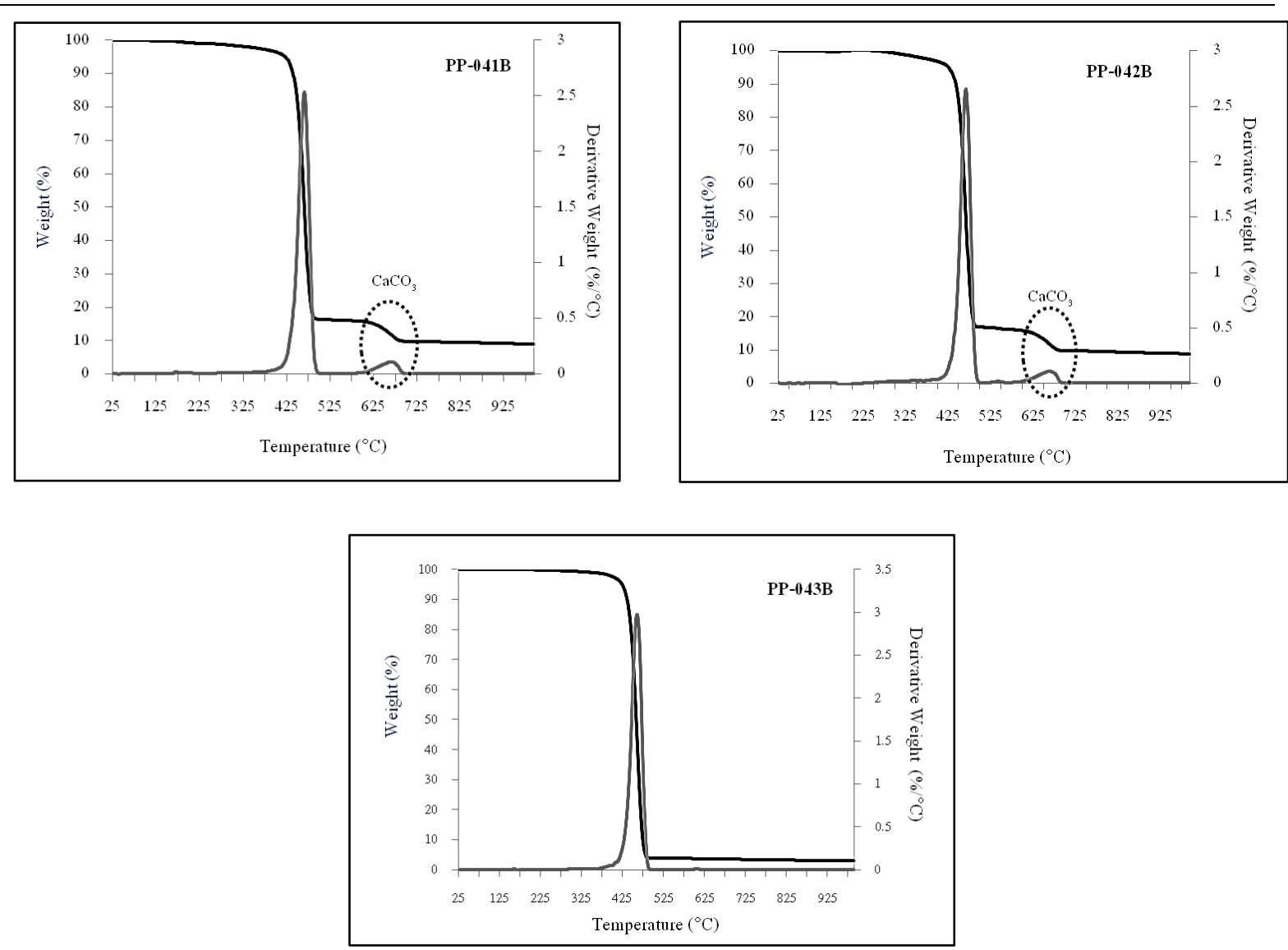

Fig. 1: TGA and DTG of different recycled PP grades.

recycled PPs were found to be similar with peak temperatures between $470-480^{\circ} \mathrm{C}$ which are higher than that of virgin PP at $450^{\circ} \mathrm{C}$ (result not shown here), indicating the thermal stability effect of CB. As a benchmark, virgin PP was hence mixed with the PP/CB master batch in order to achieve a content of $3 \mathrm{wt} \% \mathrm{CB}$, which is equivalent to that of PP-043B, and tested against other blends.

\section{Mechanical Properties}

One of the most important requirements for motorcycle saddles is to have high impact and flexural strengths as they experience impact forces during the fabrication process (stapling seat cover with the saddle) and bending stresses from a riders' weight during normal usage.
A decrease in the Izod impact strength was observed as the amount of recycled PP increased as shown in Figure 2. This may be due to the shorter chain lengths of recycled polymers compared to virgin plastics due to exposure to high shear and high temperature during previous processing. The results show that the impact strength of PP-041B blends decreased sharply as the amount of recycled $P P$ increased whereas the $P P$ 042B and PP-043B blends produced comparable impact strength to each other and decreased gradually as the recycled PP concentrations increased to $30 \mathrm{wt} \%$. A sharper decrease in the impact strength could be observed between 30-50 wt\%, and at loading of $>50 \%$ the differences in the impact strength between the three 


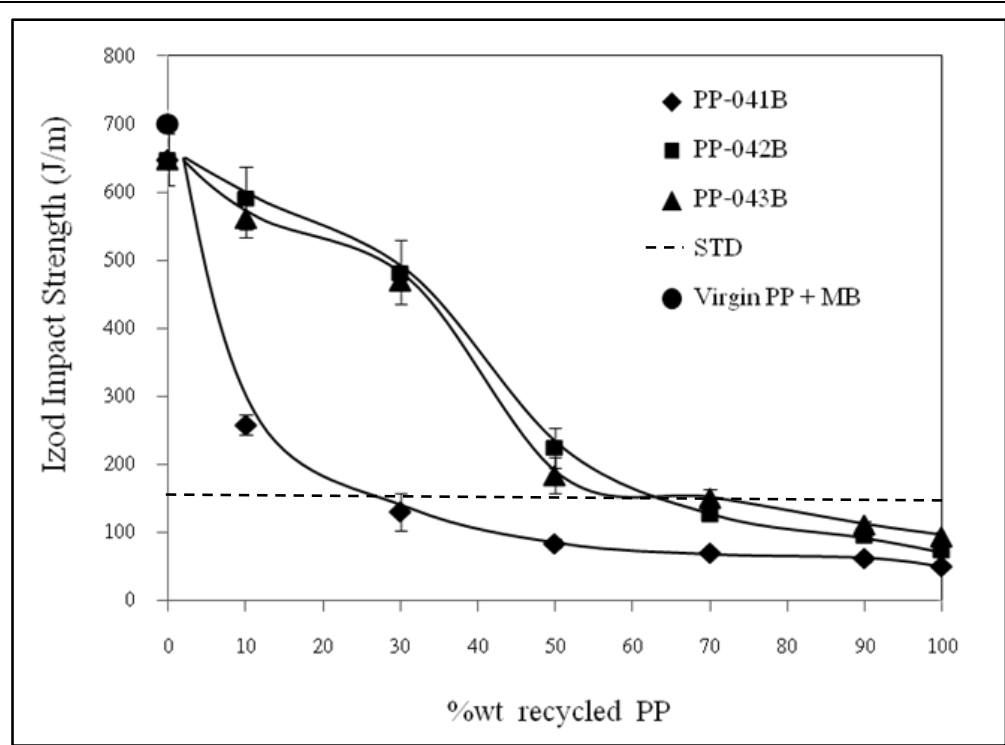

Fig. 2: Izod impact strength of different types of recycled/virgin polymer blends at different \% recycled PP (solid lines are trend lines).

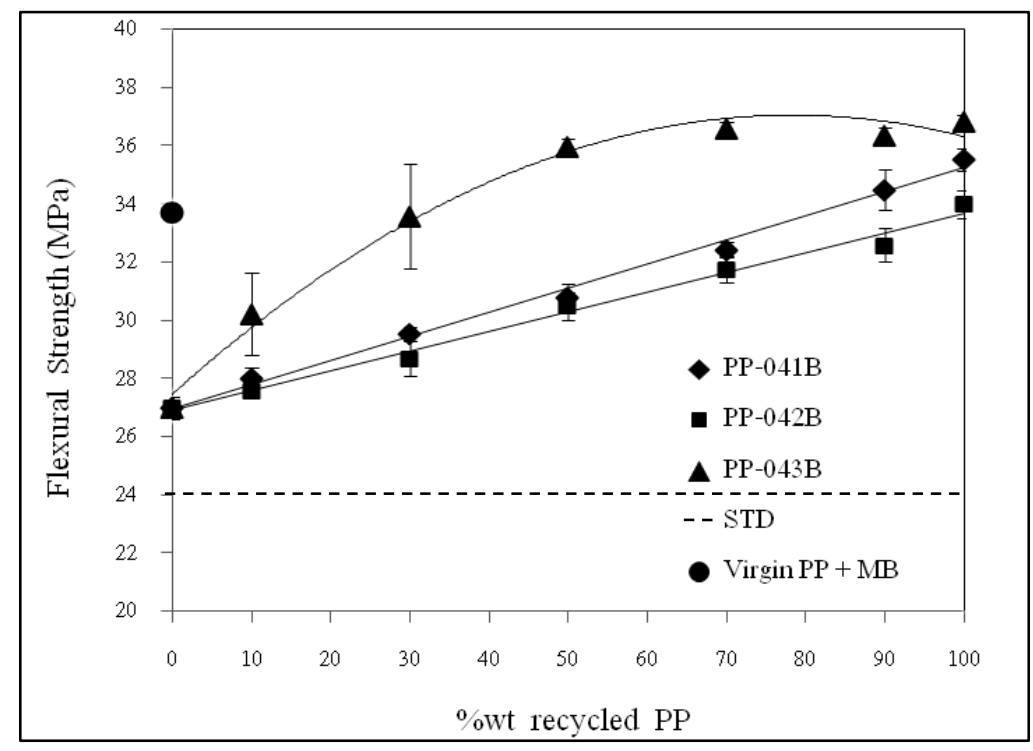

Fig. 3: Flexural strength of different types of recycled/virgin polymer blends at different $\%$ recycled PP (solid lines are trend lines).

recycled PP blends became less. When 3 wt\% $C B$ was added into virgin PP (designated as virgin $\mathrm{PP}+\mathrm{MB}$ in all the figures thereafter), a slight improvement on the impact strength compared to neat virgin PP was observed. According to motorcycle saddle standard specifications, the Izod impact strength must be over 160 $\mathrm{J} / \mathrm{m}$ which is shown as a dashed line in the figure. To meet this specification, the maximum allowable amount of PP-041B that can be included in a blend is $20 \%$ and approximately $50 \%$ for PP-042B and PP043B blends.

Unlike the detrimental effect on impact strength, the addition of recycled PP improved the flexural (see Figure $\mathbf{3}$ and 4) and tensile properties (see Figure $\mathbf{5}$ 


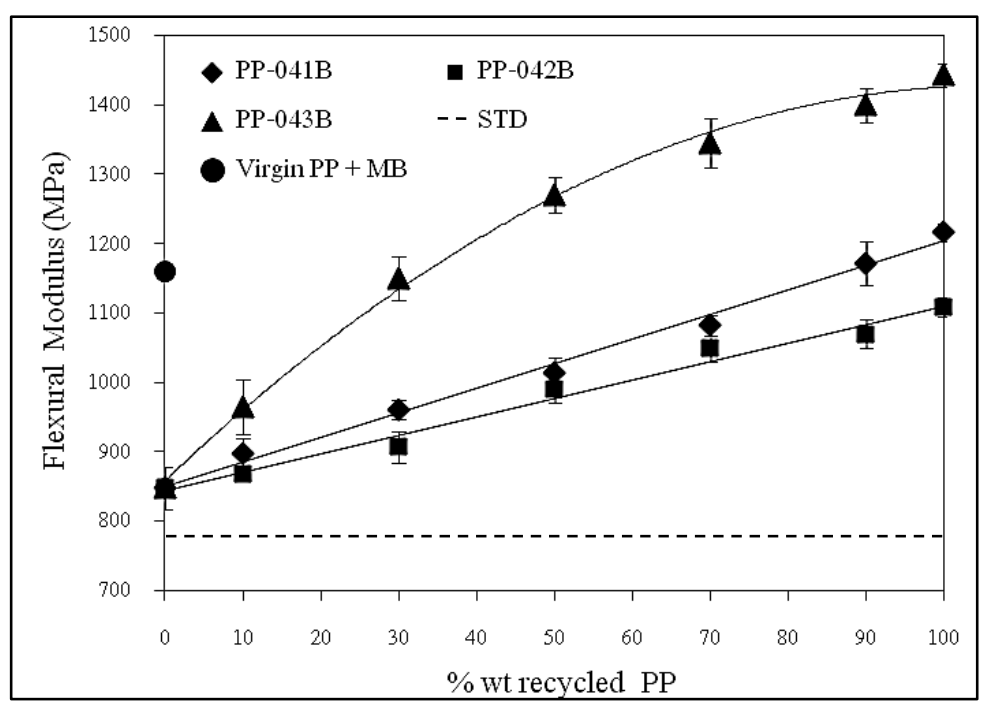

Fig. 4: Flexural modulus of different types of recycled/virgin polymer blends at different $\%$ recycled PP (solid lines are trend lines).

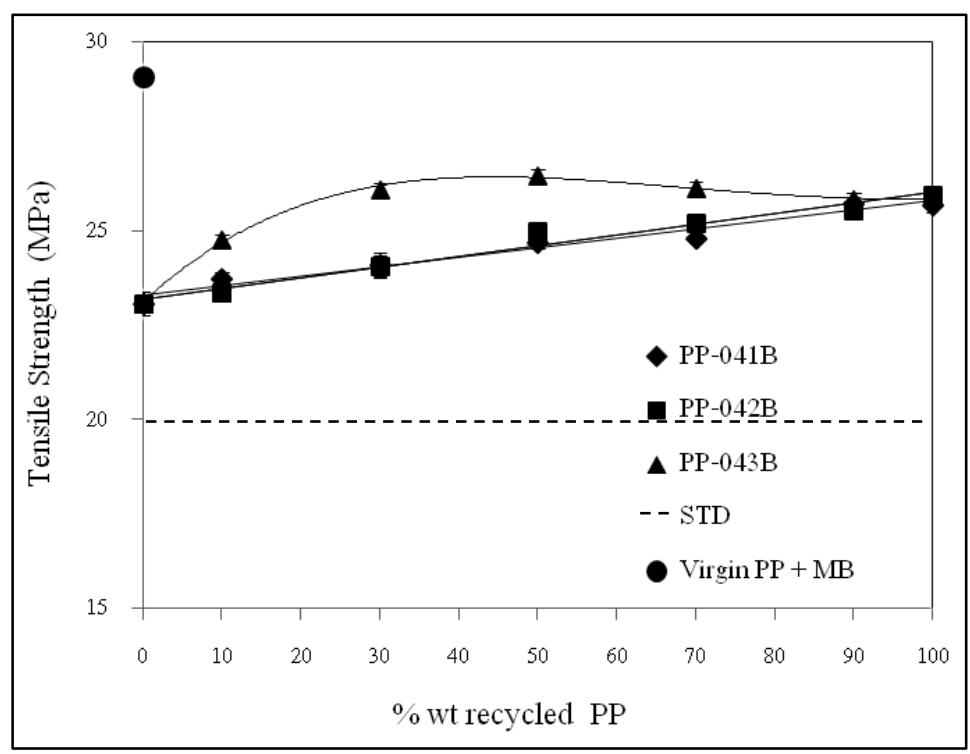

Fig. 5: Tensile strength of different types of recycled/virgin polymer blends at different $\%$ recycled PP (solid lines are trend lines).

and 6) of virgin PP. This could be attributed to the $C B$ in the recycled $P P$, which is known to be a reinforcing material. Comparison of the pure virgin PP (i.e. $0 \%$ recycled PP) with virgin PP containing $3 \mathrm{wt} \% \mathrm{CB}$ shows a considerable improvement in the flexural and tensile properties confirming the role of $\mathrm{CB}$ in enhancing these properties. The properties of the virgin PP with $3 \mathrm{wt} \% \mathrm{CB}$ were comparable to those of $100 \%$ PP041B and PP-042B which contain 10 wt\% $C B$, but lower than those of $100 \%$ PP-043B which also contains 3 wt\% $C B$, to some extent. This might be because of different grades of CB and PP in each recycled PP. Since PP-043B came from materials used in automobiles, these plastic grades are expected to have better mechanical properties. The flexural and tensile tests 


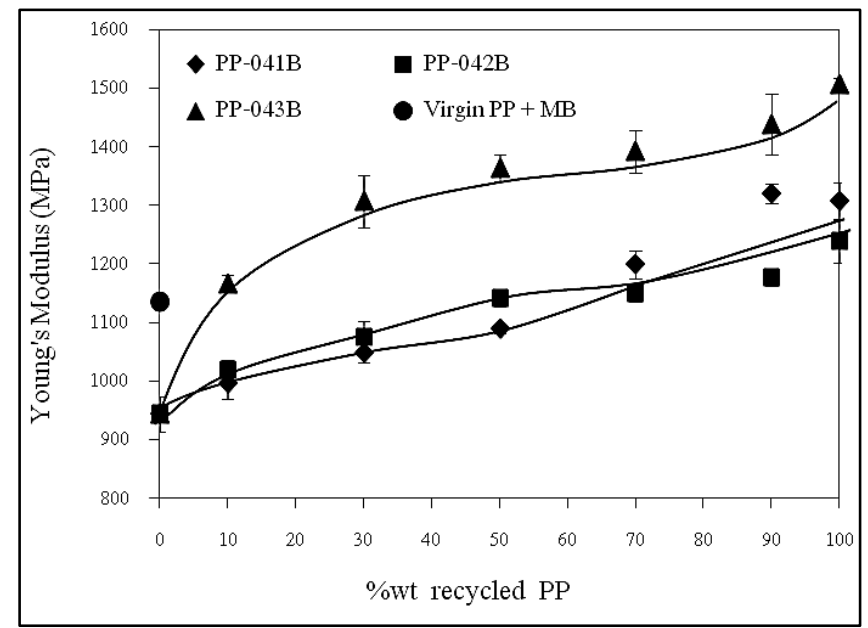

Fig. 6: Tensile modulus of different types of recycled/virgin polymer blends at different $\%$ recycled PP (solid lines are trend lines).

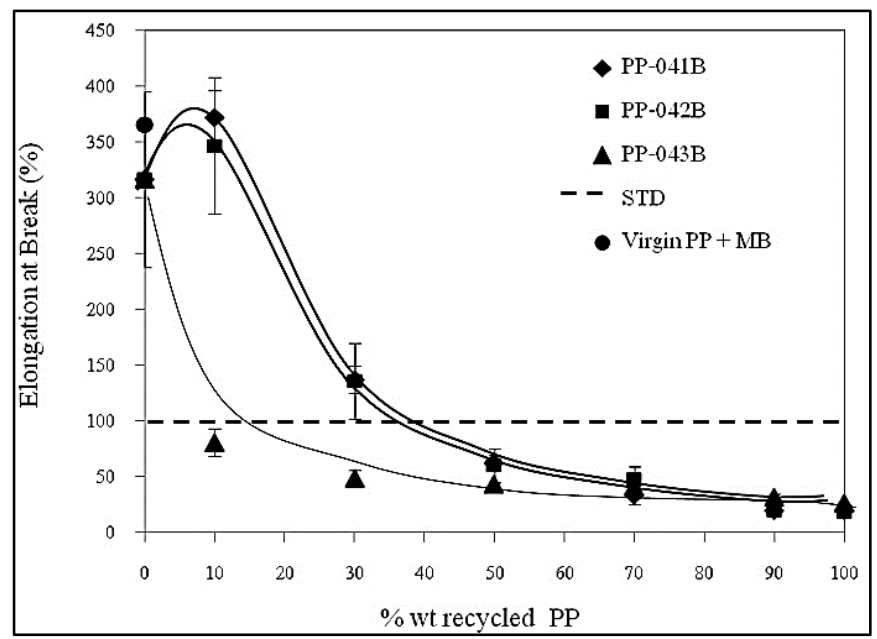

Fig. 7: Percent elongation of different types of recycled/virgin polymer blends at different \% recycled PP (solid lines are trend lines).

show that among the three recycled PPs, PP-043B was the strongest and stiffest material. By incorporating PP-043B into virgin $\mathrm{PP}$, the flexural and tensile strengths were improved considerably where they reached a maximum at approximately 50 wt\% and above which the properties plateaued and remained constant. Unlike PP-043B, the blends with added PP-041B and PP-042B displayed a linear improvement in their flexural and tensile strengths with PP content with both showing very similar results. This suggested that PP-043B was more compatible with virgin PP than the other two recycled PPs. For all the blends tested, the minimum required properties for motorcycle saddles of $24 \mathrm{MPa}$ for flexural strength, $780 \mathrm{MPa}$ for flexural modulus, and $20 \mathrm{MPa}$ for tensile strength were achieved.

It was expected that due to chain scission of the recycled PP that addition of these would be detrimental to the elasticity of the blended material and this is confirmed in Figure 7. Even though CB 


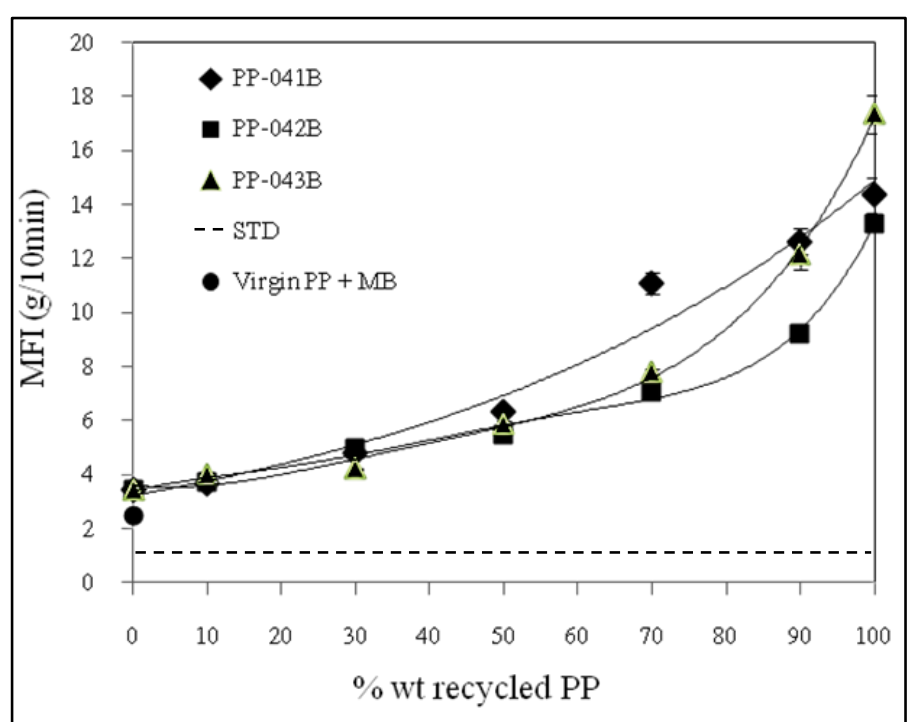

Fig. 8: MFI of different types of recycled/virgin polymer blends at different \% recycled PP (solid lines are trend lines).

is a good reinforcing material, its addition to plastics does not have a significant effect on the percent elongation at break as illustrated by the result of virgin PP with 3 wt\% CB. The percent elongation at break of the blends with PP-043B decreased sharply with minimal addition of recycled PP at $\sim 10 \%$, then decreased gradually after that. In contrast, a $10 \%$ addition of PP-041B and PP-042B initially had a positive effect on the elongation at break however a sharp decline was observed at $>10 \%$ recycled $\mathrm{PP}$. The elongation at break results for PP-041B and $\mathrm{PP}-042 \mathrm{~B}$ were very similar for all concentration tested and at the high recycled PP contents all three recycled PP produced very similar results. The standard elongation at break value is $100 \%$ for motorcycle saddles thus to meet these specifications, the maximum content allowable for PP-041B and PP-042B blends are approximately $30 \%$ and $<10 \%$ for PP043B.

Thus to conclude, in order to meet the minimum mechanical specifications required for motorcycle saddles, the maximum contents of PP-041B, PP-042B, and PP-043B in a plastic blends cannot exceed $20 \%, 30 \%$, and $10 \%$, respectively. With these maximum allowable contents for the three recycled materials the cost of raw material can be reduced by $10 \%, 13 \%$, and $5 \%$, respectively.

\section{Thermal Properties}

Thermal properties of plastics are important for determining processing conditions as well as to give some understanding of mechanical and other properties. The melt flow index (MFI) is a simple indicator of how easy a material can be processed and is also an indirect measure of molecular weight of the polymers. The molecular chains of recycled PP are shorter than virgin PP due to chain scission during earlier processes, thus, as the amounts of recycled PP increased, the molecular weight of the blends decreased, resulting in an increase in $\mathrm{MFI}$ as illustrated in Figure 8. This finding is similar results obtained by other 

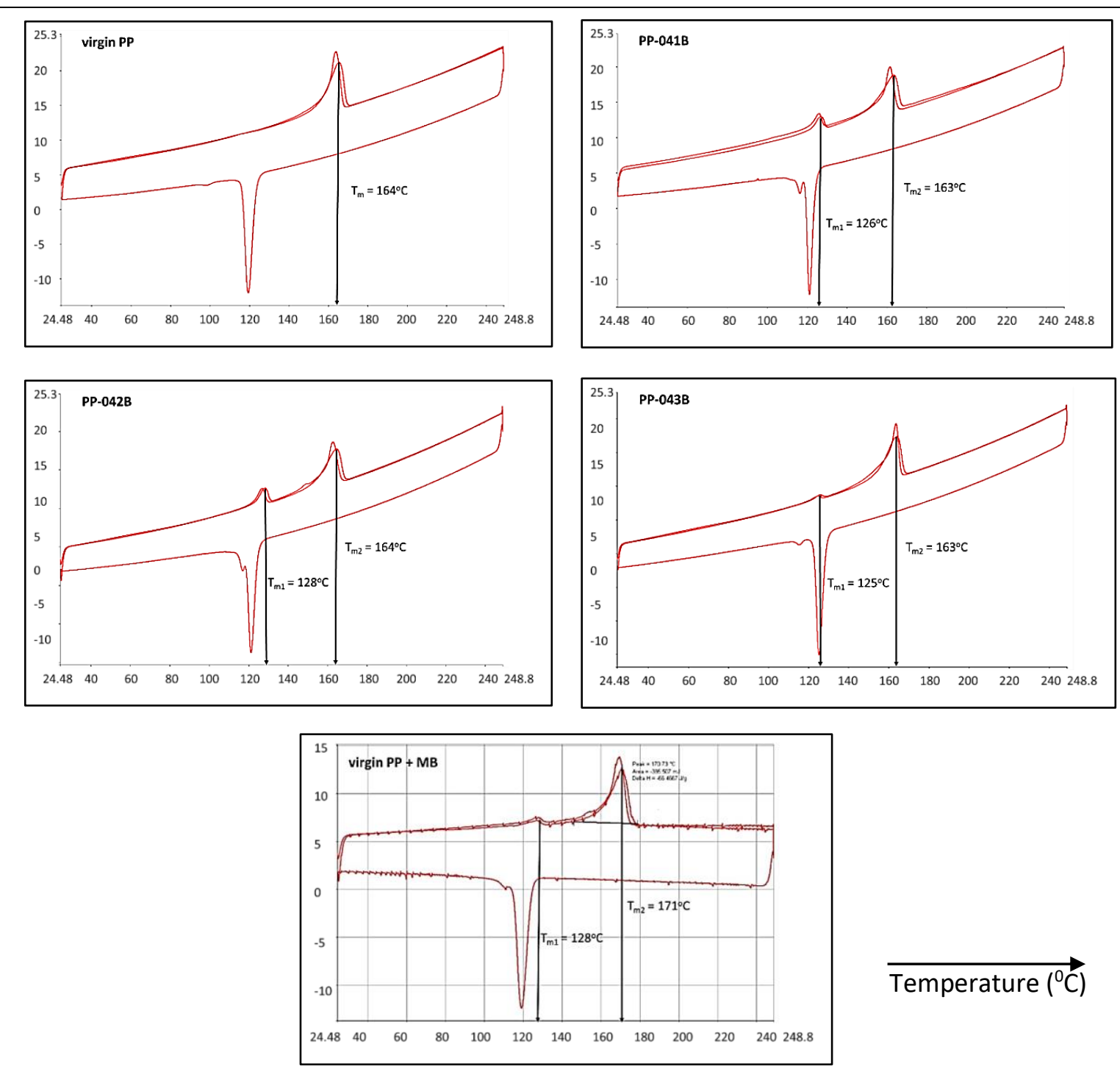

$\overrightarrow{\text { Temperature }\left({ }^{\circ} \mathrm{C}\right)}$

Fig. 9: DSC thermogram of different materials

researchers (Rust et al. 2006, Ferg and Bolo 2013). The results of MFI verified the results of the Izod impact strength and percent elongation in that the increasing amounts of recycled PP compromised these two properties due to an increase in short polymer chains from the recycled PPs. The mechanical properties results indicate that noticeable differences in properties are observed between the three recycled $\mathrm{PP}$ at low contents however at high recycled PP contents their mechanical properties become comparable. In contrast, the MFI study demonstrates visible differences at high recycled PP contents. This implies that the effect on mechanical properties is due to the nature of the recycled PPs rather than the effect of molecular weight of the blends. Presumably, the addition of $C B$ increases the blend viscosity resulting in a lower MFI value for the blend of virgin PP containing 3 wt\% CB compared to pure virgin PP (at $0 \%$ recycled $\mathrm{PP}$ ). Nevertheless, all the blends passed the minimum required MFI of $1.7 \mathrm{~g} / 10 \mathrm{~min}$.

DSC thermograms of different materials are shown in Figure 9. These provide 


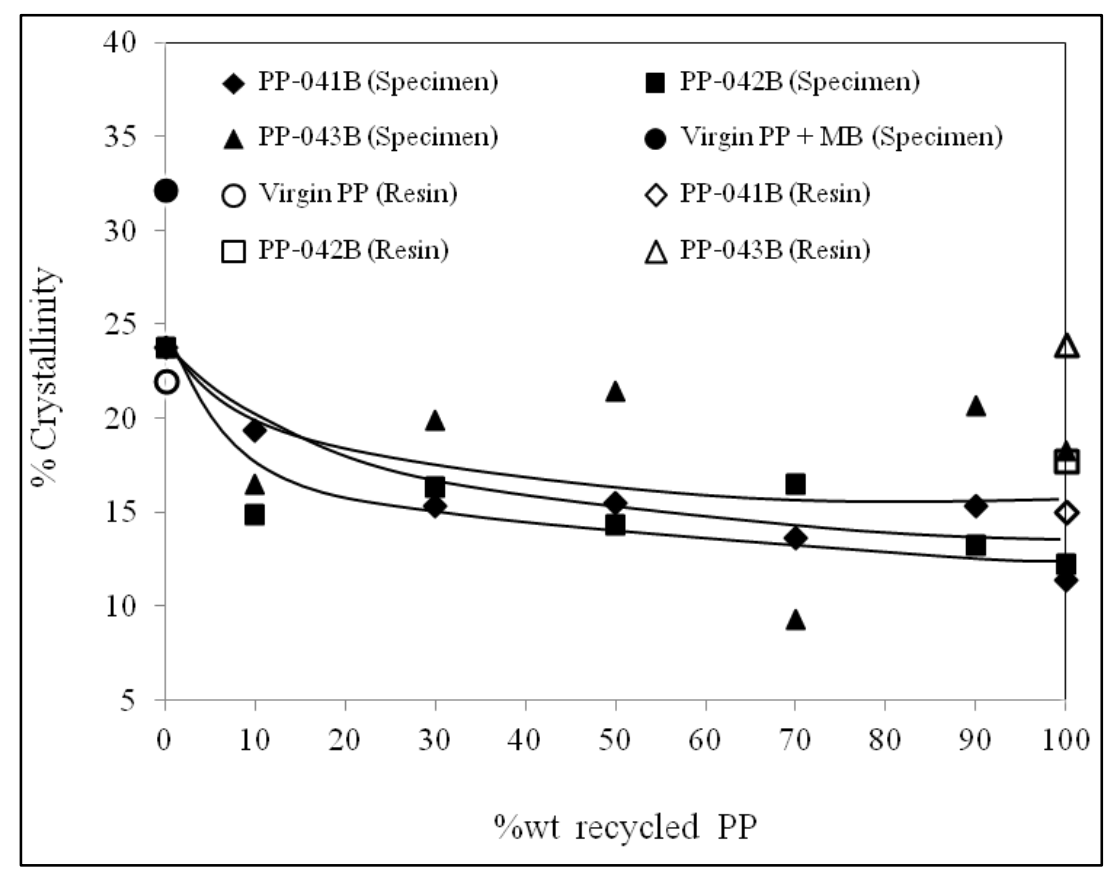

Fig. 10: Percent crystallinity of different types of recycled/virgin polymer blends at different \% recycled PP (solid lines are trend lines).

useful information on the thermal properties as well as microstructure of the blends. It was found that except for the virgin $\mathrm{PP}$, the blend of virgin $\mathrm{PP}$ with 3 $w t \% C B$ and the three recycled PPs had two $T_{m}$, one at approximately $125-128^{\circ} \mathrm{C}$ and the other between $164-171^{\circ} \mathrm{C}$. Similar results were reported in previous studies (Brachet et al. 2008, Gu et al. 2014, Ferg and Bolo 2013). A small content at the first melting temperature was likely to be polyethylene (PE) either from contamination during the waste separation process or during PP synthesis (i.e. a small amount of ethylene comonomer is usually added for PP polymerization). The fact that the $\mathrm{PE}$ melting peak can be observed on the thermogram of the virgin PP containing $C B$, but not in the pure virgin $P P$, might be because $C B$ acts as a nucleating agent for both PP and PE. This can be observed as an increase in \%crystallinity of about $10 \%$ when $C B$ was added to virgin PP as illustrated in Figure 10. However it was found that $T_{c}$ of PP was not altered as shown in Figure 11. Figure 12 showed that on the other hand, with addition of CB Tm increased by approximately $6^{\circ} \mathrm{C}$. Mucha et al. (2000) explained an increase of $T_{m}$ due to the high melting temperature $C B$ dispersed in PP amorphous matrix. However, our findings are contradictory of some research that reported an unchanged or a small increase in $\mathrm{T}_{\mathrm{m}}$ and around $10^{\circ} \mathrm{C}$ increase in $\mathrm{T}_{\mathrm{c}}$ [Madi 2013 , Liu et al. 2010, Socher et al. 2011, Mucha et al. 2000, Jiang et al. 2012).

The result also showed that \%crystallinities of the recycled/virgin blends were independent of the recycled PP concentrations. PP-043B possessed a slightly higher amount of crystallinity whereas PP-041B and PP-042B contained the same amount of crystallinity. This is reflected by the better mechanical 


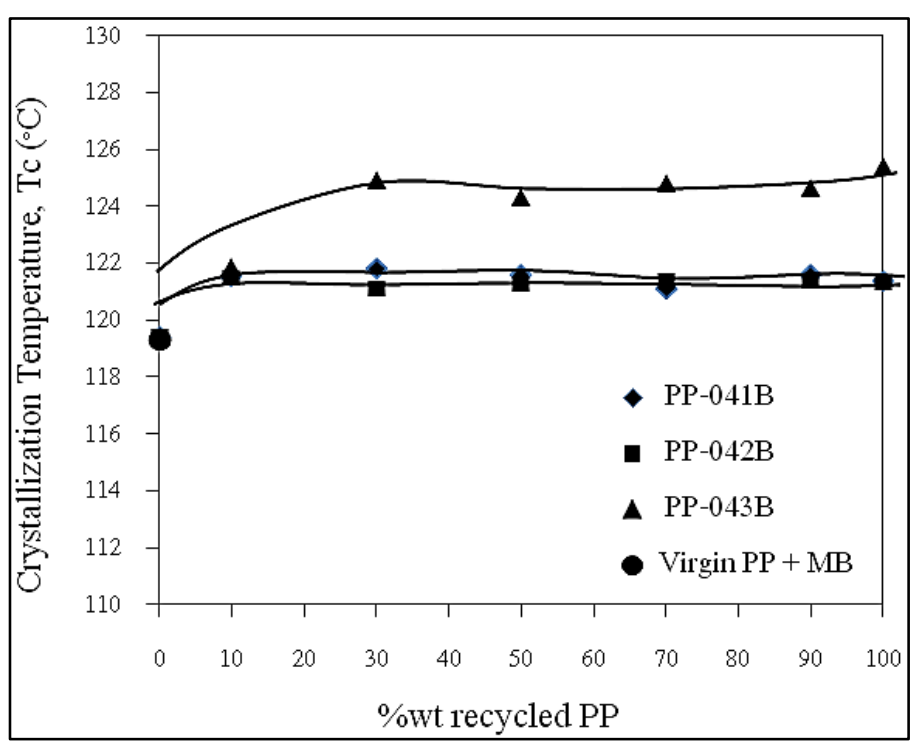

Fig. 11: Crystallization temperature of different types of recycled/virgin polymer blends at different \% recycled PP (solid lines are trend lines).

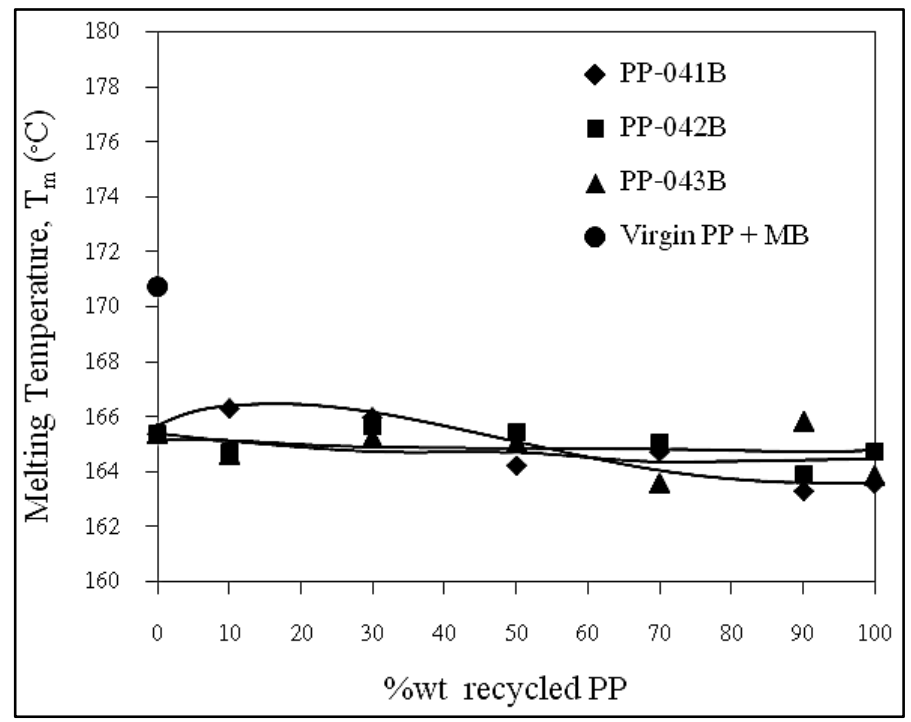

Fig. 12: Melting temperature of different types of recycled/virgin polymer blends at different \% recycled PP (solid lines are trend lines).

performances of PP-043B compared to the other two recycled PPs. However, the crystallinities of the blends as well as of pure recycled PPs were lower than that of virgin PP due to the fact that the short chains of recycled PPs are mobilized, and hence it is difficult to arrange into crystal structures. Similarly, $\mathrm{T}_{\mathrm{c}}$ and $\mathrm{T}_{\mathrm{m}}$ remained constant as the amount of recycled PPs in the blend increased. The similarity of the level of crystallinity of the blends at any compositions suggested that the improvement in mechanical properties at high recycled PP contents was a result of the increase amount of $C B$. From these thermal properties results, it can be concluded that the processing conditions does not require any changes in order to manufacture the motorcycle saddles from the recycled/virgin PP blends. 


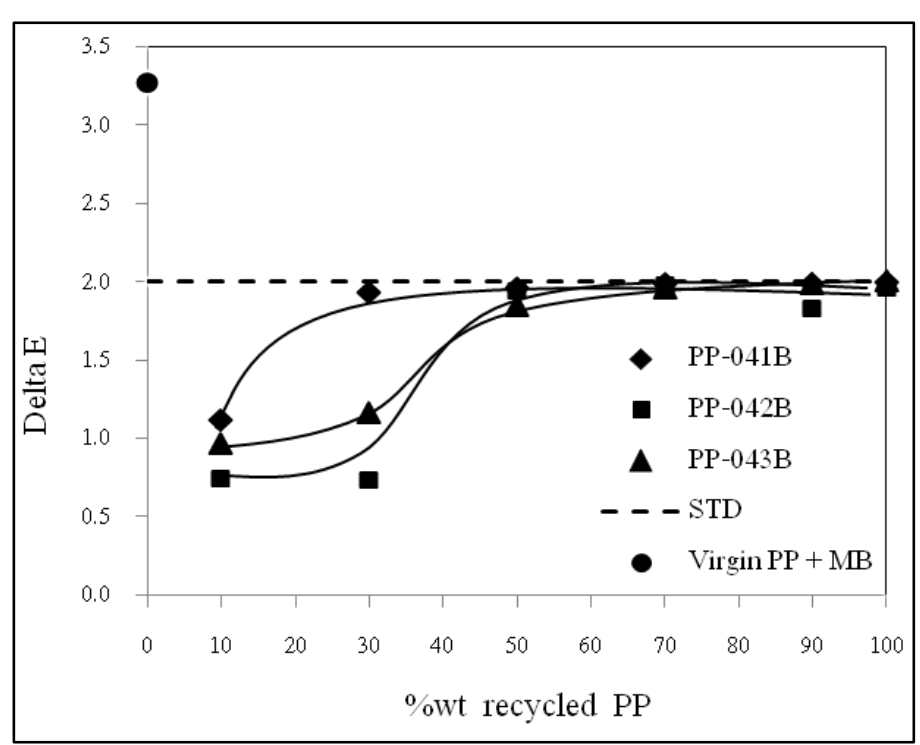

Fig. 13: Delta $E$ of different types of recycled/virgin polymer blends at different \% recycled PP (solid lines are trend lines).

\section{Color Change}

One specification required for motorcycle saddles is the CIE color of which the standard requirements are $L$ : $24.52 \pm 1.5$, a: $0.07 \pm 1.5$, and b: $0.14 \pm 1.5$. Practicality wise, it is better to measure how much the color deviates from a standard sample such that $\mathrm{dE} \leq 2.0$. Figure 13 illustrates the effect of increasing recycled PP contents on $\mathrm{dE}$. The results indicate a change in color resulting in an increase in $\mathrm{dE}$ for all three recycled PP up to $50 \%$ content after which the $\mathrm{dE}$ became constant. The maximum $\mathrm{dE}$ observed were less than 2.0 which is within the standard specification for a motorcycle saddle. The $\mathrm{dE}$ for the blend of virgin PP with 3 wt\% CB was measured at $\sim 3.3$ which is above the standard specification.

\section{CONCLUSION}

Plastic recycling is currently an important issue from an economic point of view but also due to current environmental concerns. A large numbers of researchers have been working on this topic due to the society's dependence on plastics and ways to improve their properties which generally deteriorate after being processed. One of the major obstacles of plastic recycling is the difficulty in controlling the quality of the wastes due to numerous sources. This research demonstrated the feasibility of replacing the use of $100 \%$ virgin PP with blends using recycled PP from different sources for a motorcycle saddle application. It was found that the major concern with using recycled PP was that their short molecular chains significantly affect the impact strength and percent elongation of the resulting product. As a result, the maximum amount of recycled PP that could be used to blend is limited. Two benefits of incorporating recycled PP are, firstly, the blends of the recycled PP did not require any additional carbon black as these are already incorporated in 
recycled PPs and secondly, an increase of MFI suggested an easier process whilst $T_{m}$ of the materials was not altered. Recycled PP from an automotive source (PP-043B) provided the best mechanical properties among the three recycled PPs tested although it contained the least amount of carbon black. In addition, it was found to be quite compatible with the virgin PP as it was demonstrated little effect on the properties at concentrations beyond $50 \%$. Although only a $5-13 \%$ in cost reduction could be accomplished from using blends as a replacement for $100 \%$ virgin PP, the overall positive environmental impact in terms of reusing recycled material is considered very valuable.

\section{ACKNOWLEDGEMENT}

The authors would like to thank TS Interseats Co., Ltd., Master-Tech Chemical Co., Ltd., and Sekai Color Co., Ltd. for their support regarding material and testing equipment. The authors are also very grateful for the thermal property characterization which was carried out at the Department of Materials and Metallurgical Engineering, Rajamangala University of Technology Thanyaburi, under the supervision of Assist. Prof. Dr. Sommai Pivsa-Art

\section{REFERENCES}

1. Al-Saleh, M. H., and Sundararaj, U. (2008). An innovative method to reduce percolation threshold of carbon black filled immiscible polymer blends, Composites Part A, 39, 284.

2. Brachet, P., HØydal, L. T., Hinrichsen, E.
L., and Melum, F. (2008). Modification of mechanical properties of recycled polypropylene from post-consumer containers, Waste Manage., 28, 2456.

3. Chrissafis, K., Paraskevopoulos, K. M., Stavrev, S. Y., Docoslis, A., Vassiiou, A., and Bikiaris, D. N. (2007). Characterization and thermal degradation mechanism of isotactic polypropylene/carbon black nanocomposites, Thermochim Acta, $465,6$.

4. Deng, H., Skipa, T., Zhang, R., Lellinger, D., Bilotti, E., Alig, I., and Peijs, T. (2009). Effect of melting and crystallization on the conductive network in conductive polymer composites, Polym., 50, 3747.

5. Ferg, E. E., and Bolo, L. L. (2013). A correlation between the variable melt flow index and the molecular mass distribution of virgin and recycled polypropylene used in the manufacturing of battery cases, Polym. Test., 32, 1452.

6. Gu, F., Hall, P., Miles, N. J., Ding, Q., and $\mathrm{Wu}, \quad$. (2014). Improvement of mechanical properties of recycled plastic blends via optimizing processing parameters using the Taguchi method and principal component analysis, Mater. Des., 62, 189.

7. Ha, K. H. (2012). Open-loop recycling to apply refrigerator plastics from post-consumer waste polypropylene, Mater. Des., 35, 310.

8. Jakab, E., and Omastova, M. (2005). Thermal decomposition of polyolefin/carbon black composites, J. Anal. Appl. Pyrolysis, 74, 204. 
9. Jancar, J., Douglas, J. F., Starr, F. W., Kumar, S. K., Cassagnau, P., Lesser, A. J., Sternstein, S. S., and Buehler M. J. (2010). Current issues in research on structure-property relationships in polymer nanocomposites, Polym., 51, 3321.

10. Jiang, Z., Jin, J., Xiao, C., and Li, X. (2012). Effect of surface modification of carbon black (CB) on the morphology and crystallization of poly(ethylene terephthalate)/CB masterbatch, Colloids Surf. A, 395, 105.

11. Kashiwagi, T., Grulke, E., Hilding, J., Groth, K., Harris, R., Butler, K., Shields, J., Kharchenko, S., and Douglas, J. (2004). Thermal and flammability properties of polypropylene/carbon nanotube nanocomposites, Polym., 45, 4227.

12. Liu, F., Qian, X., Wu, X., Guo, C., Lei, Y., and Zhang, J. (2010). The response of carbon black filled high-density polyethylene to microwave processing, J. Mater. Process. Technol., 210, 1991.

13. Madi, N. K. (2013). Thermal and mechanical properties of injection molded recycled high density polyethylene blends with virgin isotactic polypropylene, Mater. Des., 46, 435.

14. Marinho, B., Ghislandia, M., Tkalyac, E., Koning, C. E., and de With, G. (2012). Electrical conductivity of compacts of graphene, multi-wall carbon nanotubes, carbon black, and graphite powder, Powder Technol., 221, 351.

15. Meran, C., Ozturk, O., and Yuksel, M. (2008). Examination of the possibility of recycling and utilizing recycled polyethylene and polypropylene,
Mater. Des., 29, 701.

16. Mucha, M., Marszalek, J., and Fidrych, A. (2000). Crystallization of isotactic polypropylene containing carbon black as a filler, Polym., 41, 4137.

17. Omnès, B., Thuillier, S., Pilvin, $P$. , Grohens, Y., and Gillet, S. (2008). Effective properties of carbon black filled natural rubber: Experiments and modelling, Composites Part $A, 39$, 1141.

18. Palza, H., Vergara, R., and Zapata, P. (2010). Improving the Thermal Behavior of Poly(propylene) by Addition of Spherical Silica Nanoparticle, Macromol. Mater. Eng., 295, 899.

19. Plastic Addict Compounds (2003). On the road to recyclable cars. 5(2), 30.

20. Rajendran, S., Scelsi, L., Hodzic, A., Soutis, C., and Al-Maadeed, M. A. (2012). Environmental impact assessment of composites containing recycled plastics, Resour. Conserv. Recy., 60, 131.

21. Razavi-Nouri, M., GhorbanzadehAhangari, M., Fereidoon, A., and Jahanshahi, M. (2009). Effect of carbon nanotubes content on crystallization kinetics and morphology of polypropylene, Polym. Test., 28, 46.

22. Reffaee, A. S. A., El Nashar, D. E., AbdEl-Messieh, S. L., and Abd-El Nour, K. N. (2009). Electrical and mechanical properties of acrylonitrile rubber and linear low density polyethylene composites in the vicinity of the percolation threshold, Mater. Des., 30, 3760.

23. Reinforced Plastic (2003) Composites on the road to the big time?, 47(2), 33 . 
24. Rigamonti, L., Grosso, M., MØller, J., Sanchez, V. M., Magnani, S., and Christensen, T. H. (2014). Environmental evaluation of plastic waste management scenarios, Resour. Conserv. Recy., 85, 42.

25. Rust, N., Ferg, E. E., and Masalova, I. (2006). A degradation study of isotactic virgin and recycled polypropylene used in lead acid battery casings, Polym. Test., 25, 130.

26. Semaan, M. E., Quarles, C. A., and Nikiel, L. (2002). Carbon Black and silica as reinforcers of rubber polymers: Doppler broadening spectroscopy results, Polym. Degrad. Stab., 75, 259.

27. Socher, R., Krause, B., Hermasch, S., Wursche, R., and Pötschke, P. (2011). Electrical and thermal properties of polyamide 12 composites with hybrid fillers systems of multiwalled carbon nanotubes and carbon black, Compos. Sci. Technol., 71, 1053.

28. Sten, R. S. (1992). Polymer recycling: Opportunities and limitations, Proc. Natl. Acad. Sci. USA, 89, 835.

29. Subramanian, P. M. (2000). Plastics recycling and waste management in the US, Resour. Conserv. Recy., 28, 253.
30. Tao, Y., and Mai, K. (2007). Nonisothermal crystallization and melting behavior of compatibilized polypropylene/recycled poly(ethylene terephthalate) blends, Eur. Polym. J., 43, 3538.

31. Thaithae, W., Antonio, C., and Wattanachai, P. (2016). Properties characterisation of polycarbonate and multi-walled carbon nanotubes composites prepared by solution technique, Asia-Pac. J. Chem. Eng., 11, 34.

32. Wen, X., Wang, Y., Gong, J., Liu, J., Tian, N., Wang, Y., Jiang, Z., Qiu, J., and Tang, T. (2012). Thermal and flammability properties of polypropylene/carbon black nanocomposites, Polym. Degrad. Stab., 97, 793.

33. Zhang, J. G., Jiang, D. D., and Wilkie, C. A. (2006). Thermal and flame properties of polyethylene and polypropylene nanocomposites based on an oligomerically-modified clay, Polym. Degrad. Stab., 91, 298. 